\title{
A saúde sob o olhar do idoso institucionalizado: conhecendo e valorizando sua opinião
}

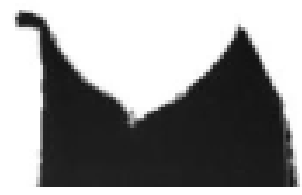

Renato Campos Freire Júnior ${ }^{1}$ Maria de Fátima Lobato Tavares ${ }^{2}$

FREIRE JR, R. C.; TAVARES, M. F. L. Health from the viewpoint of institutionalized senior citizens: getting to know and value their opinion, Interface - Comunic., Saúde, Educ., v.9, n.16, p.147-58, set.2004/fev.2005.

The objective of this study was to analyze the perceptions that the elderly from the Lar dos Idosos Monsenhor Rocha, Caratinga, MG, Brazil, elderly's home have of their own health, at this time in their lives. Towards this end, a qualitative study was undertaken with a group of elderly people - residents of that asylum -, in which they were submitted to a semi-structured individual interview. So as to arrive at a more profound comprehension of the issue, we also investigated the internal documents of the institution concerning its residents. The analysis of data from the interviews revealed very interesting findings as, for example, the comprehension and the broad perspective the subjects had concerning the concept of health. Based on this concept, the main results suggest that there is a very important relation between work, social network, spirituality, state of health and happiness. Moreover, growing old in good health and being happy are concrete possibilities for these people. The situation in which they find themselves, - institutionalized -, was able to awake, within these elderly people, feelings of nostalgia and desires that emerge as expressions of exclusion and limitations.

KEY-WORDS: Old age peoples' health; elders' health; institutionalization; health promotion.

O objetivo deste trabalho foi analisar as percepções que o idoso do Lar dos Idosos Monsenhor Rocha, Caratinga, MG, têm de sua saúde, nesta idade da vida. Para se alcançar os resultados, foi realizada pesquisa qualitativa com um grupo de idosos residentes naquela instituição, por meio de entrevista semi-estruturada individual. Para que pudéssemos chegar a uma compreensão mais profunda do assunto, acessamos também os documentos internos da instituição relacionados aos residentes. A análise das entrevistas nos revelou achados interessantes como a compreensão e a visão ampla acerca do conceito de saúde. A partir dessa compreensão, os principais resultados nos sugerem que há uma relação importante entre o trabalho, a rede social, a espiritualidade e o estado de saúde $e$ a felicidade. Além disso, envelhecer com saúde e estar feliz são possibilidades concretas para eles. A situação em que se encontram, institucionalizados, pôde despertar nesses idosos sentimentos de saudades e desejos que surgem como expressão de exclusão e limitação.

PALAVRAS-CHAVE: Saúde do idoso; institucionalização; promoção da saúde.

${ }^{1}$ Fisioterapeuta, Departamento de Administração e Planejamento em Saúde, Escola Nacional de Saúde Pública Sérgio Arouca, Fundação Oswaldo Cruz (DAPS/ENSP/FIOCRUZ). <renatocfjunior@hotmail.com>

${ }^{2}$ Pesquisadora, professora, DAPS/ENSP/FIOCRUZ. <flobato@ensp.fiocruz.br>

${ }^{1}$ Rua Leopoldo Bulhões, 1480 , sala 707

Manguinhos - Rio de Janeiro, RJ

$21.041-210$ 


\section{Introdução}

Estudos (Rodrigues et al., 2000; Teixeira, 2000; Rosa et al., 2003) vêm demonstrando uma maior preocupação com o envelhecimento populacional, especialmente em países em desenvolvimento, nos quais este fenômeno ocorre no contexto de grande desigualdade social. Nestes países, o aumento de idosos vem acontecendo de forma muito rápida, sendo estimado que em 2025 entre os dez com maior número de idosos, cinco serão países em desenvolvimento (WHO, 1998).

Nessa classificação inclui-se o Brasil que deverá ocupar a $6^{a}$ posição, e cuja faixa central está entre oitenta ou mais anos de idade, requerendo a necessidade de um sistema de saúde mais estruturado para atender a essa demanda crescente, bem como medidas urgentes por parte do governo e da sociedade em geral (WHO, 1998, Lima-Costa, 2003).

Nessa problemática, o idoso institucionalizado constitui, quase sempre, um grupo privado de seus projetos, pois encontra-se afastado da família, da casa, dos amigos, das relações nas quais sua história de vida foi construída. Pode-se associar a essa exclusão social as marcas e seqüelas das doenças crônicas não transmissíveis, que são os motivos principais de sua internação inclusive nas Instituições de Longa Permanência (ILP).

Pensadas como cenários de cuidados, as ILP ainda constituem um desafio, principalmente se contrastadas com a proposta da promoção da saúde, que se funda no empoderamento, expressos, entre outros aspectos, pelo direito à individualidade, muitas vezes interditado neste contexto.

O conceito de promoção da saúde em que se referencia este artigo está contido na carta de Ottawa (WHO, 1986) e sinaliza para uma reorganização da atenção visando assegurar a eqüidade, a articulação entre os saberes técnico e popular, para possibilitar que as comunidades e o próprio indivíduo tenham a oportunidade de conhecer e controlar os fatores que afetam e determinam sua saúde, visando escolhas mais saudáveis.

Partindo desses pressupostos, o objetivo central deste trabalho foi identificar a percepção que aquele idoso tem de sua saúde. Identificando-o como sujeito histórico, ao levar em consideração sua cultura, sentimentos e questionamentos, poder-se-ia, a partir desse conhecimento, instruir as práticas de saúde na perspectiva da promoção da saúde, contribuindo com um aporte concreto e efetivo para reorganização da atenção. Além de contribuir como primeiro passo para a superação da interdição do diálogo que em geral acontece no cotidiano das instituições e serviços de saúde.

Outro fator que sustentou a importância desta pesquisa foi o número reduzido de estudos existentes na área da saúde, com o enfoque que se quer imprimir: - desvelar o universo dos idosos brasileiros, e qual o significado que dão a esse período de sua vidas, no contexto do Lar dos Idosos Monsenhor Rocha (LIMR), localizado no município de Caratinga, Minas Gerais.

Essa instituição abriga hoje cerca de cem idosos que se encontram em vários estágios: independentes, semi - independentes e dependentes funcionalmente, sendo dividida em duas partes: uma interna, subdividida em ala masculina e feminina e outra externa. Os residentes nas alas são em sua maioria, dependentes para a realização das atividades de vida diária

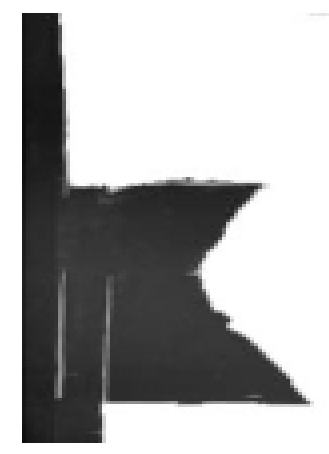


(AVD's), não possuem autonomia financeira e são tutelados pela instituição. A parte externa, localizada nos fundos das alas, é denominada Vila Ozanam e se compõe de várias moradias cedidas aos idosos, que são, em geral, independentes para as AVD's, embora suas despesas sejam também mantidas pelo LIMR.

Metodologia

Utilizou-se o método qualitativo, definindo como instrumentação uma triangulação na qual as articulações entre diversas técnicas garantiriam maior aprofundamento do assunto. Foram escolhidas, a observação participante $e$ a análise documental como técnicas complementares $e$ as entrevistas semi - estruturadas como eixo central.

A análise documental buscou descrever em detalhes o nível empírico, enfocando a estrutura do ILMR, a organização e as dinâmicas de atendimento e as características da população referida, bem como as redes de relações que conformam essa instituição. A observação participante foi registrada em um "diário de campo" e permitiu o alcance das dimensões explicativas que os dados exigem, sendo realizada ao longo de cada entrevista. Empregou-se a modalidade de Participante - Observador, segundo a classificação de Gold (1958).

Participaram das entrevistas dez idosos de ambos os sexos, a partir de 60 anos. Desses, três residiam na Vila Ozanam e sete nas alas feminina $e$ masculina. Quanto ao sexo, sete eram mulheres e três homens, com idade média de 73 anos. Oito residiam na instituição há mais de cinco anos e todos se nomearam católicos.

A amostragem seguiu os princípios do estudo qualitativo, no qual a unidade de análise é o conjunto dos entrevistados. Utilizou-se o índice de saturação (Bertaux, 1980) definido como o fenômeno pelo qual, passado certo número de entrevistas, o pesquisador tem a impressão de que a apreensão do objeto está contemplada em suas semelhanças e diferenças.

\section{Resultados e discussão}

\section{o "olhar" para a saúde}

$\mathrm{Na}$ construção do conceito de saúde, os entrevistados abordaram aspectos físicos, sociais e mentais, denotando compreensão de que saúde não é apenas a ausência de doença: "Saúde é a gente comer bem, beber bem, dormir bem... e tudo mais..." (D. Yasmin).

A capacidade funcional, a autonomia $e$ a independência foram os principais fatores destacados, estando ligados ao fato de poderem trabalhar, na consideração do próprio trabalho como medidor do estado de saúde: " $A$ gente ter saúde é bom que pode trabalhar, vai prá todo lugar que quiser ir..." (Sr. Cravo). "A saúde é a gente ser forte, ter expediente pra trabalhar...” (D. Branca).

Rodrigues et al. (2000) destacam a saúde e a doença nos idosos como fenômenos clínicos e sociológicos que são dependentes, entre outros fatores, da situação econômica e social, na qual a velhice é demarcada principalmente pela aposentadoria e pela "desqualificação" como mão - de - 
obra para o mercado de trabalho. Em continuação, ressaltam que há uma transição de ruptura com o mundo produtivo, transpondo-se da categoria de trabalhador para ex-trabalhador; de cidadão ativo para inativo, com reflexo negativo para seu estado de saúde. Teixeira (2000) denomina essa situação como falência social e coloca essa saída involuntária do mercado de trabalho como um processo contrário ao empoderamento ${ }^{3}$, podendo causar também, vulnerabilidade psicológica e emocional.

Quatro idosos expressaram ainda como sinônimo de saúde, a ausência de dor e outros sintomas. Suas respostas se referiam à experiência atual, o que numa análise mais atenta evidencia que os sintomas que os incomodam são mais importantes do que a doença propriamente dita: "Olha, é a gente não sofrer dor, como eu vivo sofrendo, né?..." (Sr. Cravo). "Saúde é a gente num sofrer nada... mas eu sofro um danado de uma asmática, quando me bate eu fico ruim mesmo..."(Sr. Marrom).

É interessante notar que todos eles são portadores de doença crônica incapacitante, apresentando sintomas álgicos com freqüência. Sobressaiu o não entendimento dessas patologias e da necessidade diária da medicação, além da referência da cura de suas incapacidades como situação - objetivo a ser alcançada: "Tomo muito remédio...mas por enquanto ainda num acertei não..." (Sr. Azul).

A análise dos documentos internos e dos prontuários, no entanto, constatou que a medicação e o tratamento são adequados, e que o atendimento é realizado por equipe multidisciplinar. Essa referência então pode sinalizar inexistência de informação mais competente quanto a essas questões. Carvalho et al. (1998) acharam repostas semelhantes em seu trabalho e acrescentaram que essa forma de pensar é especialmente prejudicial para o sucesso terapêutico.

Veras et al. (2002) destaca a importância de políticas e modelos de promoção da saúde que não apenas previnam os efeitos deletérios da incapacidade funcional, mas que permitam a compreensão da morbidade pelos idosos, de modo que desenvolvam processo de empoderamento, capaz de favorecer oportunidade de controle de sua própria saúde, não mais esperando que vivam uma vida passiva.

Pode-se entender, porém, que a experiência de cada um no sofrimento $e$ na dor estabeleceu uma forma singular de ver a saúde. "A experiência da doença, necessariamente, implica alterações no modo de vida pessoal $e$ social, podendo conter a adoção de estratégias e novas percepções sobre essa nova situação" (Gomes \& Mendonça, 2002, p.117).

Uma das entrevistadas que está há menos de um ano no LIMR apontou a saúde como sinônimo da relação entre felicidade e liberdade, bens recentemente perdidos: "É a gente se sentir feliz... E de maneira que a gente tá num tem alegria com nada, igual eu num tenho... Porque eu num tô querendo ficar aqui, eu quero ir embora" (D. Cristalina).

Rodrigues et al. (2000) destacam como aspectos influentes nesta discussão o ambiente, entendido como físico, econômico, social. Minayo (1992, p.14) conceitua de forma ampla a saúde, incorporando a felicidade e o ambiente: "Saúde significa bem estar e felicidade: ela própria, explicitamente ou no "silêncio do corpo" é a linguagem preferida de
${ }^{3}$ Empoderamento - É um pressuposto da promoção da saúde, segundo o qual indivíduos, comunidades e organizações obtêm controle sobre os fatores que afetam sua saúde (Teixeira, 2000). 
harmonia e do equilíbrio entre o indivíduo, a sociedade e seu ecossistema".

A religiosidade e a espiritualidade estiveram presentes na fala dos idosos para conceituar saúde e ao longo das entrevistas, quando a definiram como algo transcendente, estabelecida por Deus e fora de seu controle. Apreende-se de suas falas que eles se colocam de forma passiva diante da saúde, com um certo conformismo: "Saúde é a gente pegar com Deus... O remédio num vale prá nada se num pegar com Deus...” (D. Branca; Sr. Cravo). É inegável o papel desempenhado pela religião no enfrentamento das exigências da velhice, facilitando a aceitação das perdas, sendo, por isso, um dos recursos utilizados em situações difíceis.

Mais da metade dos entrevistados respondeu que se sentia saudável, relacionando o "estar saudável" com a presença de uma rede de apoio e de relacionamento interpessoal: "Sinto que eu sô saudável porque a gente tem muitos amigos, né? Muita alegria... a gente conversa com um, com outro"(D. Branca).

Alguns autores (Sluzki, 1997a; Valla, 2000) confirmam que o apoio social contribui para manutenção da saúde das pessoas, aumentando a sobrevida $e$ acelerando os processos de cura; além de permitir a superação de certos acontecimentos como a morte de alguém da família, a perda da capacidade de trabalhar, a perda de papéis sociais, o despejo da casa ou mesmo a institucionalização, entre outros. Assim, a rede de apoio e o convívio com outras pessoas podem ser entendidos como verdadeira estratégia de sobrevivência.

Isto se destacou nos relatos de duas entrevistadas que tiveram várias chances de voltar para sua própria casa ou a de um familiar, se recusaram, afirmando que não poderiam ficar longe dos amigos e das pessoas do LIMR.

Para a maioria, a idade em que se encontram não interfere em sua saúde, embora três tenham atribuído àquela, o aparecimento de sinais e sintomas incapacitantes, expressos pela imagem do corpo, pela menor agilidade, pela perda da força: "( $A$ doença) Atrapalha porque... a gente já nem tem força igual a gente tinha quando novo... (Sr. Marrom).

Motta (2002) descreve que os idosos apresentam clara percepção dos processos dessas perdas, muitas vezes tratadas como problemas de saúde, o que é reforçado pelo imaginário social, de forma preconceituosa.

Ficou claro, pois, que eles dissociam idade e saúde, daí não ser difícil entender porque quase todos consideraram ser possível desfrutar de uma vida saudável e feliz, apresentando até mesmo certa naturalidade com relação ao processo de envelhecimento: "Tem gente mais velha do que eu que tá andando numa esperteza..." (D. Branca). "Eu era mais doente que agora, que eu tô de idade, eu tô com saúde..." (D. Margarida). Embora essa última fala expresse um estado de saúde hoje melhor do que quando era mais jovem, trata-se de uma senhora que sofreu amputação da perna esquerda há apenas quatro meses.

Foi ressaltado o estilo de vida, colocando a responsabilidade sobre si próprio: "viver uma vida correta e boa..." (Sr. Cravo). A convivência com tolerância também foi citada de forma consistente, como um dos fatores para se envelhecer feliz e saudável.

Para os profissionais de saúde que lidam com essa população é muito 
importante estar atento a suas respostas, mesmo contraditórias, pois elas ressaltam que envelhecer numa Casa Lar nem sempre é sinônimo de perda, mas sim uma etapa da vida em que se pode desfrutar com alegria e bem - estar.

Reforçando essa questão, o comentário de uma idosa quando perguntada se é possível envelhecer feliz e saudável: “... É possível. É dizer que eu sofro... eu sô doente, mas sô feliz! Num vô importar com meu sofrimento... vou viver feliz!...” (D. Yasmim). Ela tem diagnóstico de artrite reumatóide, encontrandose presa a uma cadeira de rodas e apesar de todas as suas limitações, vem conseguindo tecer e bordar tapetes, embora apresente as deformidades crônicas e clássicas dessa patologia em ambas as mãos. Com o dinheiro da venda desses tapetes compra objetos pessoais e assim consegue estabelecer uma atitude de independência, diferindo da grande maioria de seus colegas cuja renda provém da aposentadoria, que fica sob a responsabilidade da instituição.

Uchoa (2003, p.852) afirma que "a avaliação da gravidade e da relevância de um problema de saúde parece ser mais claramente determinado pela possibilidade de enfrentá-los, muito mais que pelo problema em si”.

Alguns idosos associaram o processo de envelhecimento com a perda da autonomia: "... Então a gente vai fracassando... aí fica dependendo de uma coisa, dependendo de outra... depende de uma pessoa prá fazer aquilo..." (D. Cristalina).

De maneira geral, pode-se concluir que os idosos não consideram o envelhecimento somente como um período de perdas e sofrimentos, nem tampouco como sinônimo de doença, buscando viver essa fase da vida, valorizando determinados aspectos que possam amenizar as perdas.

A vida institucionalizada: reflexões e saudades

A transferência do próprio lar para uma instituição de longa permanência (ILP) é sempre um grande desafio para os idosos, pois se deparam com uma transformação muitas vezes radical do seu estilo de vida, sendo desviados de todo seu projeto existencial. Segundo Born (1996), muitos idosos encaram o processo de institucionalização como perda de liberdade, abandono pelos filhos, aproximação da morte, além da ansiedade quanto à condução do tratamento pelos funcionários. Contudo, não devemos esquecer que, muitas vezes, essa ILP cumpre papel de abrigo para o idoso excluído da sociedade e da família, abandonado e sem um lar fixo, podendo se tornar o único ponto de referência para uma vida e um envelhecimento dignos.

Suas respostas quanto ao que mais sentiam falta em sua vida antes da institucionalização, foram quase unânimes, quando destacaram sentir saudades do trabalho, dos amigos e dos parentes.

Longer \& Rodin (apud Teixeira, 2000) demonstraram os efeitos positivos no estado e na saúde de idosos institucionalizados ao se aumentar o sentido de responsabilidade e de controle de suas próprias vidas, afirmando que os problemas ligados ao processo de envelhecimento podem estar na falta desse controle, quase sempre agravados pela institucionalização.

Cabe, pois, refletir um pouco mais sobre a importância do trabalho / ofício entre outros fatores, para bem estar destes idosos institucionalizados, para que 
as estratégias de intervenção em sua saúde e qualidade de vida possam ser eficazes, trazendo os benefícios esperados tanto pelos profissionais de saúde, quanto por eles.

Outro ponto importante já abordado neste estudo é a relação com outras pessoas, mais precisamente com os parentes e amigos. Sabemos que a rede social pessoal apresenta uma tendência a diminuir à medida em que se envelhece, necessidade que pode se tornar mais intensa quando tratamos do idoso institucionalizado. Associa-se a isto a redução das oportunidades de substituição para essas perdas: "Eu sinto falta é dos meus amigos, né? tá tudo longe, a gente num pode ver eles, né?" (Sr. Azul). "É de lá do lugar que eu tava morando, lá no meio das minhas colegas, no meio dos amigos, então eu sinto falta de lá. É tanto que não vim aqui pra morar. Eu vim prá recuperação, por causa do tombo que tomei..." (D. Cristalina).

Para Sluzki (1997b, p.118): "se vêem cada vez mais recolhidas nas relações familiares que carregam consigo suas próprias velhas histórias de lealdade, de dúvidas e esperanças de retribuição de compromissos e ciúmes, de paixões escondidas".

As instituições têm o papel fundamental de atuar como mediadoras $e$ promotoras dessa rede social. Os idosos entrevistados perceberam que o LIMR se preocupa em trabalhar para que essas perdas de vínculos sejam atenuadas, colocando-se como importante elo de uma rede de apoio, além de contribuir para que se estabeleçam novas relações entre os internos: "Não! Num sinto (falta) não, porque hoje eu tô mais tranqüila, que algum tempo eu trabalhei na roça, né?... E hoje meu serviço é só em casa, né? o que eu puder ajudar o outro na casa dele também eu ajudo... (D. Margarida).

Com relação ao que sentem necessidade para que tenham uma boa vida, seis idosos afirmaram como necessidade o trabalho e o dinheiro. A resposta desses idosos é pertinente uma vez que 98\% dos residentes na parte interna e 93,3\% dos residentes na Vila Ozanam possuem uma renda familiar de até um salário mínimo (Da Silva \& Santa Clara, 2003). Este quadro ainda se torna mais marcante para os idosos devido à perda da autonomia financeira, visto que, como já analisado anteriormente, são tutelados pela instituição.

Mais uma vez foi observado um processo de desempoderamento (Teixeira, 2000) e que é percebido pelos idosos. Sem dúvida alguma, a perda da autonomia financeira e do trabalho se enquadram perfeitamente dentro desses fatores: "A gente pensa em muitas vezes, que se tivesse dinheiro a vida tava melhor, né? Falta do dinheiro..." (D. Branca).

\section{O significado da felicidade}

Segundo Paschoal (2000), avaliar a própria vida para saber se é boa ou ruim é um processo intra - psíquico complexo, abrangendo julgamentos, emoções e projeções para o futuro. Os fatores pessoais e ambientais bem como a saúde e a doença se relacionam na interpretação do indivíduo, determinando de que maneira e o quanto ele valoriza e se sente satisfeito com sua vida. Essa satisfação irá depender não apenas da sensação de prazer e ausência de sofrimento, mas também terá como contribuição esperança, visão de futuro, significado, persistência e auto eficiência.

Nordenfelt (apud Paschoal, 2000) elege a felicidade como o principal fator a 
ser identificado com qualidade de vida, pois ela é o mais geral dos conceitos de bem estar, ligando-se de forma muito íntima às vontades e objetivos das pessoas. Desta maneira, alguém é feliz porque seus desejos e objetivos são, ou estão sendo realizados. Para este autor, como os objetivos tendem a ser múltiplos são feitas escolhas e este sentimento floresce quando o objetivo julgado prioritário já foi preenchido.

A partir dessas constatações é que pode ser compreendido porque oito dos dez idosos entrevistados responderam que se consideravam pessoas felizes. Em suas respostas evidenciou-se a priorização da rede de apoio e a boa convivência alcançada, como significativos para seu bem estar. Desta forma, seria como se este objetivo superasse todos os outros problemas e isso os preenchesse com um sentimento de felicidade. Não há dúvida, portanto, quanto ao fato de as relações interpessoais serem importantes $e$ essenciais na vida deles. Uchôa et al (2002) destacam que em vários relatos das idosas que entrevistaram, foi possível identificar uma busca ativa de redes de solidariedade extra - familiares.

Na pergunta sobre o que tirariam ou colocariam em sua vida para que ela melhorasse, $o$ aspecto econômico foi o principal elemento destacado por eles. O desejo de uma moradia melhor, por exemplo, foi algo muito citado: "A gente pensa que arrumar uma casinha maior, controlar direitinho, comprar uns móveis melhor, né?” (D. Branca). A saúde também foi lembrada pelos idosos: "Ah... mais saúde quanto puder, né? Quanto mais a gente pôr saúde é melhor, né?" (Sr. Azul). Para outros, a possibilidade de voltar à mocidade, renovando a vida e o vigor: "Mas é claro né! Se tivesse jeito da gente renová a vida, e vortá assim ao normal, é bem melhor, né?" (D. Cristalina). Debert (1998) chama a atenção para os perigos desse pensamento, no qual a idéia de juventude eterna, incorporada pelos idosos que negam a velhice, pode dificultar a vivência desta etapa da vida, ao transformar os problemas da idade, doença e morte, em responsabilidade individual.

Nenhum dos idosos respondeu que tiraria algo de sua vida para que ela melhorasse. Assim, suas respostas foram sempre voltadas para o acréscimo: "Tirar...? Eu num posso tirar nada! Ah... eu num tenho nada pra tirar, ué!" (Sr. Cravo).

Medos: uma questão de superação?

Leme (1998) descreve muito bem o medo e a velhice, apontando a morte e o sofrimento como os grandes mistérios da história humana. Procurando identificar seus medos e buscar uma relação dos mesmos com a saúde e o processo de envelhecimento, introduziu-se nas entrevistas uma pergunta bem direta: - Qual é o seu maior medo?

Mais uma vez nos surpreenderam as falas. Além de três idosos terem respondido não ter medo de nada, observou-se que a grande maioria faz questão de mencionar não temer a morte, apesar de não se ter perguntado de forma direta isso a eles: "Medo? É de ficar sofrendo. Porque... o medo da morte eu num tenho não. Da morte num precisa ninguém ter medo! Que esse dia chega mesmo, né?" (D. Yasmim).

Philibert (apud Duarte, 1998) já afirmava que a morte como realidade 
concreta, nem sempre é temida pelos idosos, que podem encará-la como a libertação de uma vida destituída de significado e amor humano. Por um lado, analisando-se o contexto da história de vida desses idosos, essa afirmação caberia para a interpretação de suas falas; por outro, não deve ser esquecido o valor religioso cultuado por eles.

Com relação aos outros medos levantados, surgem como principais, a dependência e a perda da autonomia: "É de ficar prostrada na cama aqui, num ter força prá levantar, tomar um banho sozinha, e... aí isso eu tenho muito medo" (D. Cristalina). Esse medo pode ser relacionado ao processo de envelhecimento, e pode-se dizer que essa percepção se apresenta de maneira muito pertinente. Rosa et al. (2003) identificaram entre outros, as relações interpessoais, as atividades sócio-culturais, o morar sozinho e o nível de escolaridade, como indicadores importantes de capacidade funcional entre os idosos. Lembrando que estes idosos se encontram institucionalizados, podese perceber que há um risco importante de perda da autonomia.

Merece também ser destacado que duas idosas referiram que seu maior medo foi a possibilidade de se tornarem vítimas da violência: "Medo? Ce sabe qual é o maior medo que eu tenho? É de morrer de desastre... e tenho medo de tiro" (D. Margarida). Isto pode sinalizar que, de alguma maneira, esses idosos não estão alheios aos acontecimentos externos, principalmente os residentes na Vila Ozanam. E também pode demonstrar que o fato de estarem em uma ILP, não necessariamente os torna alienados.

Desejos, sonhos e anseios.

Abordam-se aqui as categorias extraídas da última pergunta do protocolo, cujo objetivo foi registrar anseios e desejos dos idosos. Sobressaíram temas tais como, casa própria, saúde, trabalho e autonomia financeira, seguidos pela felicidade e a presença de amigos: "Primeiro pedir a Deus saúde... a felicidade e amizade com todos... ser assim uma pessoa livre, tranqüila... se isso pudesse acontecer era muito bão!” (D. Cristalina).

"Ah... viver com saúde né? Trabalhando... e se a gente tivesse a casa da gente... um imovelzinho..." (D. Clara).

A gente tem vontade de voltar pra casa ué... vontade de ter junto com os amigos da gente, né?... e mais é ter um pouquinho de dinheiro também..." (Sr. Azul).

Esse foi mais um achado importante, uma vez que se pôde interpretar esses desejos e anseios como possíveis ferramentas para que os idosos busquem a autonomia $e$ a independência, refletindo esperança de um porvir.

\section{Considerações finais}

Este trabalho buscou entender os idosos institucionalizados, a partir da valorização e credibilidade de suas representações. Sem dúvida alguma, a necessidade e o interesse de se estudar e conhecer esse idoso vem aumentando a cada dia, uma vez que muitas lacunas ainda devem ser preenchidas e muitas perguntas respondidas. De acordo com os resultados encontrados, considera-se como principais o que segue.

Ao pensar em saúde, os idosos conseguem ultrapassar o sentido de 
ausência de doença. Dentro de suas limitações sócio - culturais e do nível de escolaridade, abordaram o bem -estar físico, mental e social, destacando inclusive a importância da espiritualidade e religiosidade no enfrentamento dos vários sofrimentos e dificuldades da vida.

$\mathrm{O}$ aspecto econômico e social teve influência em suas falas sobre saúde. $\mathrm{O}$ trabalho e a boa convivência, entendendo esta última como representada pelas relações interpessoais e pela rede de apoio, se destacaram em suas opiniões, apresentando-se como uma espécie de "indicadores de saúde". $\mathrm{Na}$ verdade, são fatores que incorporam como valores essenciais para manter uma vida feliz e saudável.

Apesar de apresentarem, em sua grande maioria, uma história cercada por limitações e sofrimentos, sua satisfação está muito mais ligada à superação das dificuldades e obstáculos impostos, do que propriamente à ausência deles. Os idosos do LIMR não ignoram seus problemas $e$ sofrimentos mas, ao contrário, os encaram com certa naturalidade, buscando muitas vezes a espiritualidade e a religiosidade como suporte e sustentação para enfrentá-los.

Conseguem estabelecer uma distinção entre saúde e velhice, afirmando que não há interferência direta do aumento da idade com o estado de saúde. Contudo, reconhecem a maior probabilidade de perdas e limitações com o próprio envelhecimento.

De modo geral, os idosos - alvo da pesquisa se consideraram felizes. A rede de apoio e a boa convivência representaram as grandes chaves para alcance desta felicidade, segundo sua visão de mundo. Além disso, é importante ressaltar que a instituição pôde proporcionar esses fatores $e$ desenvolver o papel de promotora da saúde e bem-estar de seus internos.

É muito claro, no entanto, a necessidade de se buscar estratégias que coloquem o idoso como coadjuvante no processo de promoção e bem-estar de sua vida, para que possamos tornar realidade a prática dos conceitos de promoção da saúde dentro deste ambiente, meta que hoje é um grande desafio para os profissionais gerontólogos que se preocupam com esta problemática.

\section{Referências}

BERTAUX, D. L approche biographique. Sa validité méthodologique, ses potentialités. In: BERTAUX, D. Cahiers Internationaux de Sociologie. Paris: Presses Universitaires de France, 1980. v.69, p.197225.

BORN, T. Cuidado ao idoso em instituição. In: PAPALÉO NETTO, M. (Org.) Gerontologia: a velhice e o envelhecimento em visão globalizada. São Paulo: Atheneu, 1996. p.403-14.

CARVALHO, F.; TELAROLLI JÚNIOR, R. ; MACHADO, J. C. M. S. Uma investigação antropológica na terceira idade: concepções sobre a hipertensão arterial. Cad. Saúde Pública, v.14, n.3, p.617-21, 1998.

DA SILVA, A. N. A.; SANTA CLARA, N. S. Perfil dos idosos institucionalizados e prevalência de dependência em uma instituição de longa permanência da cidade de Caratinga - MG. Caratinga, 2003. Trabalho de conclusão de curso (graduação) - Faculdade de Fisioterapia de Caratinga, FUNEC. 
DEBERT, G. G. Antropologia e o estudo dos grupos e das categorias de idade. In: MORAIS, M.; BARROS, L. (Org.) Velhice ou terceira idade? Estudos antropológicos sobre identidade, memória e política. Rio de Janeiro: Editora Fundação Getúlio Vargas, 1998. p.49-67.

DUARTE, M. J. R. S. Autocuidado para a qualidade de Vida. In: CALDAS, C. P. (Org.) A saúde do idoso: a arte de cuidar. Rio de Janeiro: Editora UERJ, 1998. p.17-34.

GOLD, R. Roles in sociological fields observations. Soc. Forces, n.36, p.217-23, 1958.

GOMES, R.; MENDONÇA, E. A. A representação e a experiência da doença: princípios para a pesquisa qualitativa em saúde. In: MINAYO, M. C. S. (Org.) Caminhos do pensamento: epistemologia e método. Rio de Janeiro: Editora Fiocruz, 2002. p.109-32.

LEME, L. E. G. O idoso, a morte e o sofrimento. Acta Ortop. Bras., v.6, n.1, p.29-32, 1998.

LIMA-COSTA, M. F. Epidemiologia do envelhecimento no Brasil. In: ROUQUAYROL, M. Z.; ALMEIDA

FILHO, N. (Orgs.) Epidemiologia e Saúde. Rio de Janeiro: Medsi, 2003. p.499-514.

MINAYO, M. C. S. O desafio do conhecimento: pesquisa qualitativa em Saúde. São Paulo: Hucitec/ Abrasco, 1992.

MOTTA, A. B. Envelhecimento e sentimento do corpo. In: MINAYO, M. C. S. (Org.) Coleção

Antropologia e Saúde: antropologia, saúde e envelhecimento. Rio de Janeiro: Editora Fiocruz, 2002. p.37-50.

PASCHOAL, S. M. P. Qualidade de vida do idoso: elaboração de um instrumento que privilegia sua opinião. 2000. Dissertação (Mestrado) - Faculdade de Medicina, Universidade de São Paulo, São Paulo.

RODRIGUES, R. A. P.; MARQUES, S.; FABRíCIO, S. C. C. Envelhecimento, saúde e doença. Arq. Geriatr. Gerontol., v.4, n.1, p.15-20, 2000.

ROSA, T. E. C.; BENÍCIO, M. H. D.; LATORRE, M. R. D. O.; RAMOS, L. R. Fatores determinantes da capacidade funcional entre idosos. Rev. Saúde Pública, v.37, n.1, p.40-8, 2003.

SLUZKI, C. E. De como a Rede Social afeta a saúde do indivíduo e a saúde do indivíduo afeta a Rede Social. In: SLUZKI, C. E. (Org.) A rede social na prática sistêmica: alternativas terapêuticas. São Paulo: Casa do Psicólogo, 1997a. p.67-85.

SLUZKI, C. E. A extinção progressiva da galáxia: a rede social na velhice. In: SLUZKI, C. E. (Org.) A rede social na prática sistêmica: alternativas terapêuticas. São Paulo: Casa do Psicólogo, 1997b. p.117-26.

TEIXEIRA, M. B. Empoderamento de idosos em grupos direcionados à promoção da Saúde. 2000. Dissertação (Mestrado) - Escola Nacional de Saúde Pública, FIOCRUZ, Rio de Janeiro.

UCHÔA, E. Contribuições da antropologia para uma abordagem das questões relativas à saúde do idoso. Cad. Saúde Pública, v.19, n.3, p.849-53, 2003.

UCHÔA, E.; FIRMO, J. O. A.; LIMA-COSTA, M. F. F. Envelhecimento e saúde: experiência e construção cultural. In: MINAYO, M. C. S. (Org.) Coleção Antropologia e Saúde: antropologia, saúde e envelhecimento. Rio de Janeiro: Editora Fiocruz, 2002. p.25-35.

VALLA, V. V. Redes sociais, poder e saúde à luz das classes populares numa conjutura de crise. Interface - Comunic., Saúde, Educ., v.4, n.7, p.37-56, 2000

VERAS, R. P.; LOURENÇO, R.; MARTINS, C. S. F.; SANCHEZ, M. A.; CHAVES, P. H. Novos paradigmas do modelo assistencial do setor saúde: consequência da explosão populacional dos idosos no Brasil. In: VERAS, R. P. (Orgs.) Terceira idade: gestão contemporânea em Saúde. Rio de Janeiro: RELUMEDUMARÁ/UnATI/UERJ, 2002. p.11-79. 
FREIRE JR, R. C.; TAVARES, M. F. L.

WORLD HEALTH ORGANIZATION. Carta de Ottawa. In: BRASIL. Ministério da Saúde. FIOCRUZ.

Promoção da Saúde: Cartas de Ottawa, Adelaide, Sundsvall e Santa Fé de Bogotá. Brasília: MS/IEC, 1986. p.11-8.

WORLD HEALTH ORGANIZATION. Population aging: a public health challenge. Geneva: WHO Press Office, 1998.

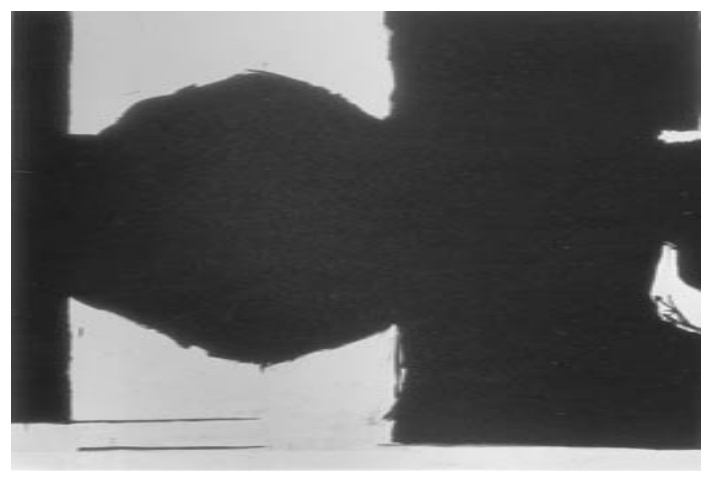

FREIRE JR, R. C.; TAVARES, M. F. L. La salud desde el punto de vista del anciano institucionalizado: conociendo y valorizando su opinión, Interface - Comunic., Saúde, Educ., v.9, n.16, p.147-58, set.2004/fev.2005.

El objetivo de este trabajo fue analizar las percepciones de los ancianos del Asilo Monseñor Rocha (LIMR) sobre su salud en esa etapa de su vida. Para ello, fue realizado un estudio cualitativo con un grupo de ancianos residentes en esa institución, mediante entrevista semiestructurada individual y, para poder llegar a una comprensión más profunda, también tuvimos acceso a los documentos internos de la institución relacionados con los ancianos residentes. El análisis de las entrevistas nos reveló hallazgos muy interesantes como, por ejemplo, su entendimiento y visión amplia acerca del concepto de salud. Los principales resultados sugieren que hay una relación importante entre el trabajo, la red social, la espiritualidad y el estado de salud y la felicidad. Además, envejecer con salud y estar feliz son posibilidades concretas para ellos. La situación en que se encuentran, institucionalizados, puede despertar en esos ancianos sentimientos de nostalgia y deseos que surgen como expresión de exclusión y limitación.

PALABRAS CLAVE: Salud del anciano; institucionalización; promoción de la salud. 